\title{
JUNCTION POTENTIALS IN RESPONSE TO ORTHO- AND ANTI-DROMIC STIMULATION OF HYPOGASTRIC NERVE IN MOUSE VAS DEFERENS
}

\author{
Hironori NAKANISHI* and Hiroshi TAKEDA \\ Shionogi Research laboratory, Shonogi \& Co. Ltd.. \\ Fukushimathu. Osaka 553. Japan
}

Accepted November 20, 1974

\begin{abstract}
The interaction of the junction potentials in response to ortho- and antidromic hypogastric nerve stimulation in mouse vas deferens was studied, using an extracellular recording method. Ortho-dromic repetitive hypogasiric nerve stimulation $(10 \mathrm{H} z, 5 \mathrm{~min})$ simultaneously depressed the amplitude of the junction potentials in response to both ortho- and anti-dromic hypogastric nerve stimulation (post-telanic depression). No time-lag in recovery from the post-tetanic depression was observed between the junction potentials recorded from two separate electrodes, indicating that the proximodistal axonal flow of available transmitter was nor involved in the recovery process. Double shocks, with intervals from $10 \mathrm{mscc}$ to $1 \mathrm{sec}$, were applied to the hypogastric nerve. The junction potentials in response to ortho- and ortho-dromic or anti- and anti-dromic double shock were markedly facilitated. On the contrary, the junction potentials in response to ortho- and anti-dromic double shocks were not facilitated. The findings indicatc that facilitation of the junction potentials is produced by the impulses propagated in the same dircetion along the terminal axom and also that the origin of the facititation may be at a pre-junctionil sile.
\end{abstract}

Burnstock and flolman (1) first recorded junction potentals in response 10 bypogastric nerve stimulation in guinea-pig vas deferens. The junction potentials showed a marked facilitation. The origin of the facilitation may be presynaptic, and not due to an increase in the sensitivity of the smooth muscle membrane to a constant amount of transmitter (2). On the other hand, adrenergic nerve libers innervating the musculature of the vas deferens make many varicosities along the length of terminal axons (3). Furness (4) confirmed that chemical transmitter was released from the varicositics, from the result that anti-dromic propagation of action potentials atong the terminal nerve fihers produced junction potentials in mouse vas deferens. The present study, therefore, dealt with the interaction of the junction potentials in response to ortho- and anti-dromic stimulation of hypogastrie nerve fibers innervatiner the museular layer of mouse vas deferens. A preliminary account of the investigation has already appeared (5).

\section{MATERIALS AND METHODS}

Male mice, weighing 20 to $25 \mathrm{~g}$, were stunned by a blow on the had, and bled from bilateral common carotid arteries. One side of vas deferens with the associated hypo-

* Present address: Department of Pharmacology, Fukushima Medical College, Sugizuma-cho, Fukushima, Japan. 
gastric nerve was removed and immersed in Krebs-Ringer bicarbonate solution, which was aerated with a mixture of $95^{\circ} \% \mathrm{O}_{2}$ and $5 \% \mathrm{CO}_{2}$, and kept at about $37^{\circ} \mathrm{C}$. The composition of the solution was as follows: $\mathrm{NaCl}, 119 \mathrm{mM} ; \mathrm{CaCl}_{2} \cdot 2 \mathrm{H}_{2} \mathrm{O}, 2.5 \mathrm{mM} ; \mathrm{KH}_{2} \mathrm{PO}_{4}$, $1.2 \mathrm{mM} ; \mathrm{KCl}, 4.7 \mathrm{mM} ; \mathrm{MgSO}_{4} \cdot 7 \mathrm{H}_{2} \mathrm{O}, 1.2 \mathrm{mM} ; \mathrm{NaHCO}_{3}, 25 \mathrm{mM}$; glucose, 11 $\mathrm{mM}$. In order to record the electrical activity of the vas deferens extracellularly, a glass capillary was used. The top of this was about $10 \mu$ in diameter and it was filled with 4 $\mathrm{M} \mathrm{NaCl}$. The mass electrical response was recorded using DC amplifiers (Nihon Koden MZ-4 and AVH-2). The indifferential electrode, which consisted of silver wire, was placed in the medium. The electrical activities were displayed and photographed using an oseilloscope (Nihon Koden VC-7) and long recording camera (Nihon Koden PC-2B). Extraand intra-mural nerve fibers existing near the prostatic and testicular ends of the vas deferens were stimulated with square wave pulses $(0.1$ to $1.0 \mathrm{msec}$ in duration and 3 to 6 $\mathrm{V}$ in intensity) through a pair of silver electrodes. For stimulation of preganglionic fibers, the stimulating electrode was placed on the central side from the prostatic ends of seminal vesicle and vas deferens.

\section{RESULTS}

1) Junction potentials in response to ortho-dromic hypogastric nerve stimulation

The hypogastric nerve was stimulated on the central side and the peripheral side from the angular part of seminal vesicle and vas deferens. Junction potentials with marked facilitation in response to stimulation of the central side were depressed by treatment with pentolinium $\left(2: 10^{-5} \mathrm{~g} / \mathrm{ml}\right)$, a ganglionic blocking agent, while the response to stimulation of the peripheral side was unaffected (Fig. 1). This finding indicates that mouse hypogastric nerve has a ganglionic relay near the prostatic end of the vas deferens. There is much evidence for such a ganglion in the running process of the hypogastric nerve in mammals (6-8). When double shocks were given to the post-ganglionic nerve, the junction potential in response to the second shock was augmented. When the interval of the double shock was shorter than $150 \mathrm{msec}$, a spike potential associated with the twitch of

EFFECT OF PENTOLINIUM

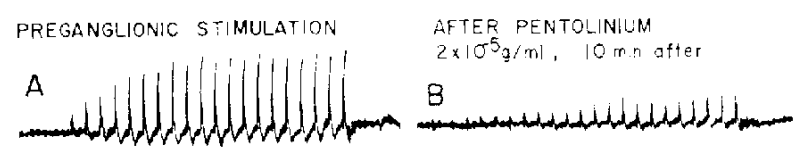

POSTGANGLIONIC STIMULATION

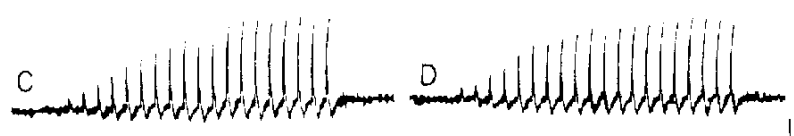

Fix. 1. Efiect of pentolinium $\left(2 \times 10^{-5} \mathrm{~g} / \mathrm{ml}\right)$ on junction potentials markedly facilitated in response to preganglionic (upper figures) and post-ganglionic (lower figures) repetitive hypogastric nerve stimulation at a frequency of $2 \mathrm{~Hz}$, in mouse vas deferens. Time calibration; $1 \mathrm{sec}$, Voltage calibration; 100 " V. 


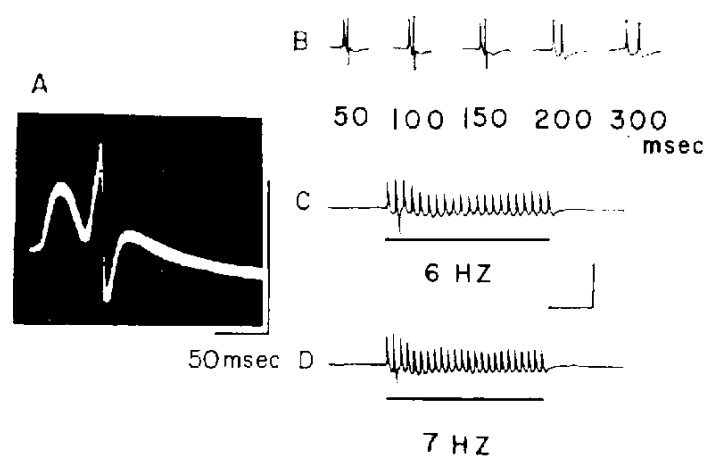

FIci, 2. A biphasic spike potential was sometimes produced by double shocks when the interval between shocks was shorter than $150 \mathrm{msec}$ ( $\mathrm{A}$ and $\mathrm{B}$ ). The spike potential was also produced by repetitive hypogastic nerve stimulation at relatively higher frequency. The facilitation of junction potentials elicited by a relatively higher frequency (usually more than 3 to $5 \mathrm{~Hz}$ ) of repetitive hypogastric nerve stinulation was followed by depression (C and D). Time calibralion : $50 \mathrm{msec}$ in $\mathrm{A}$ and $\mathrm{I} \mathrm{sec}$ in $\mathrm{B}, \mathrm{C}$ and $\mathrm{D}$, Voltage calibration ; $100, \mathrm{~V}$.

the muscle was sometimes elicited by the second shock (Fig. 2). The facilitation of the junction potentials in response to the repetitive hypogastric nerve stimulation with a frequency of more than $5 \mathrm{~Hz}$ was generally followed by depression (Wedenski's depression).

\section{2) Junction potentials in responsc to anti-dromic hypogastric nerve stimulation}

From the finding that the latency increases linearly with the distance between stimulating and recording electrodes, independent of the direction of the propagation, Furness (4) concluded that junction potentials elicited centrally from the stimulating site are caused by transmitter released with anti-dromic propagation of action potentials along the terminat nerve fibers. Zieher and Jaim-Excheverry (9) found that the prostatic side of rat vas deferens is more densely innervated by adrenergic fibers than the testicular side by measuring the noradrenaline content of the tissue. The amplitude of the junction potentials in response to stimulation of the hypogastric nerve on the prostatic side of the recording electrode was almost unaffected by shifting the positions of the stimulating electrodes. On the contrary. the amplitude of the junction potentials in response to stimulation of hypogastric nerve on the esticular side of the recording elctrode was altered according to the distance between recording and stimulating electrodes. The closer the stimulating elcctrode was to recording position, the larger was the amplitude of the junction potentials (Fig. 3). The current spread of junction potentials near stimulating electrode may not be involved in the increase of the amplitude, because the space constant of guinca-pig vas deferens is $2.1 \mathrm{~mm}$ (10). It may be that the number of fibers to be stimulated does increase as the stimulating electrode approaches the recording position on the testicular side of the vas deferens. The finding also indicates that the junction potentials in response to stimulation of hypogastric nerve at the peripheral side of the recording position may be due to release of transmitter from the varicosities acconding to the excitation of terminal fibers induced by anti-dromic stimulation. The junction potentials in response to anti- 


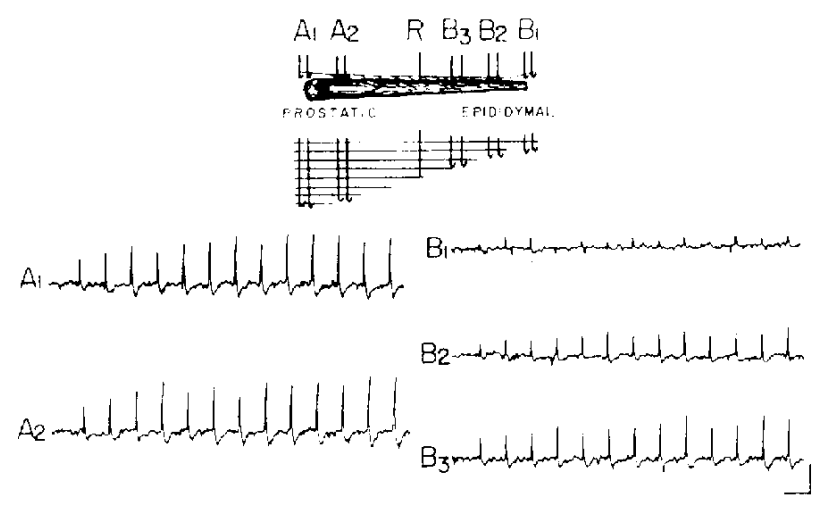

Fici, 3. Junction potentials in response to ortho-dromic $\left(A_{1}\right.$ and $\mathbf{A}_{2}$ ) and anti-dromic $\left(\mathbf{B}_{1}, \mathbf{B}_{2}\right.$ and $\mathbf{B}_{3}$ ) hypogastric nerve stimulation $(\mathbf{l} \mathrm{Hz})$ in mouse vas deferens. The amplitude of junction potentials in response to stimulation at the prostatic side of the recording electrode was almost unchanged by shifting the position of stimulation $\left(A_{1}\right.$ and $\left.A_{2}\right)$; while the amplitude of junction potentials in response to stimulation at the testicular side of the recording electrode was increased by shifting the stimulating electrode from $B_{1}$ to $B_{2}$, and $B_{3}$ (5 mm apart from recording electrode. The increase in the amplitude of junction potentials may be explained by an increase in the number of excited nerve fibers. Time calibration; $1 \mathrm{sec}$, Voltage calibration ; $100 \% \mathrm{~V}$.

dromic repetitive stimulation $(0.1$ to $10 \mathrm{~Hz})$ of the hypogastric nerve also showed marked facilitation.
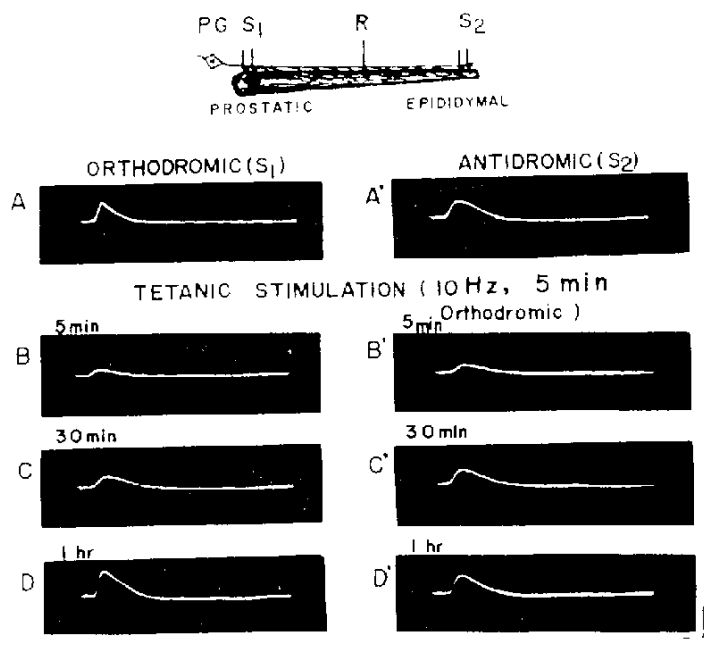

Fici. 4. Effect of ortho-dromic repetitive hypogastric nerve stimulation $(10 \mathrm{~Hz}, 1$ msec, $5 \mathrm{~min}$ ) on the amplitude of junction potentials in response to orthodromic and anti-dromic hypogastric nerve stimulation. Left ; junction potential in response to ortho-dromic stimblation. Right: junction potential in response (c) inti-tromic stimulation. A amd $\Lambda^{\prime}$ : Control, $B$ and $B^{\prime} ; 5$ min after, $C$ and $C^{\prime} ; 30$ min after, $D_{\text {and }} D^{\prime}:$ I hr after ortho-dromic tetanic stimulation, respeclively. Time calihration; 30 mece, Voltage calibration; $100, " V$. 
i) Interaction botwecen jumction potemials in response to ortho- and ant-dromic hypogastric neve stimulation

Ortho-dromic tetanic stimulation $(10 \mathrm{~Hz}, 1 \mathrm{msec}, 5 \mathrm{~min})$ of the hypogastric nerve depressed the amplitude of the junction potentials in response to both ortho- and antidromic hypogastric nerve stimulation (Fig. 4). The finding would indicate that post-tetanic depression of the junction potentials occurs locally, at the nerve terminals or postjunctional membrane. This finding also showed the existence of definite interaction between synapses excited by ortho- and anti-dromic nerve stimulation. Recovery of the amplitude of the junction potentials from post-tetanic depression produced by ortho-dromic stimulation, was observed simultaneously in ortho- and anti-dromic stimulation. Simultaneous recovery of the amplitude of the junction potentials from post-tetanic depression was observed when recorded by 1 wo electrodes $1 \mathrm{~cm}$ apart; viz. there was no timelag in the recovery of the amplitude of junction potentials recorded at the two electrodes. This finding may indicate that proximo-distal axonal flow of chemical transmitter is not involved in the recovery of the amplitude of junction potentials from post-tetanic depression. As previously described, the junction potentials in response to both ortho- and anti-dromic repetitive stimulation $(0.1$ to $10 \mathrm{~Hz})$ of hypogastric nerve showed marked facilitation. However, the junction potentials in response to alternating ortho- and antidromic stimulation of the hypogastric nerve, using the double shock method, were not facilitated (Fig. 5). When the interval between two shocks was reduced to less than $50 \mathrm{msec}$, the amplitude of junction potentials in response to the second shock was slightly reduced. This desensitization phenomenon indicates that the present mass recording of electrical activity can detect the interaction between synapses excited by ortho- and anti-dromic nerve

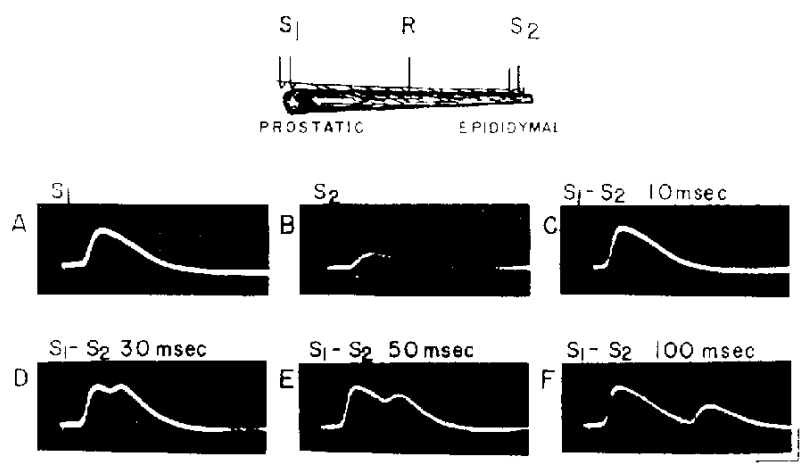

Fici. 5. Junction potentials in response to ortho- and anti-dromic double shock in mouse vas deferens. A ; junction potential elicited by a single ortho-dromic shock. B; junction potential clicited by a single anti-dromic shock. Orthodromic shock followed by anti-dromic shock; the interval of double shock was $10 \mathrm{msec}(\mathrm{C}), 30 \mathrm{msec}$ (D) and $50 \mathrm{msec}$ (E) and $100 \mathrm{msec}$ (F), respectively. The junction potential elicited by the second shock (anti-dromic) was nol angmented as a result of the preceding orlho-dromic shock. The amplitude of the junclion potential elicited by the second shock was slightly depressed when the interval of the double shock was shorter than $50 \mathrm{msec}$. Time calibration ; 50 misec, Voltiare calibration: In): $\mathrm{V}$. 


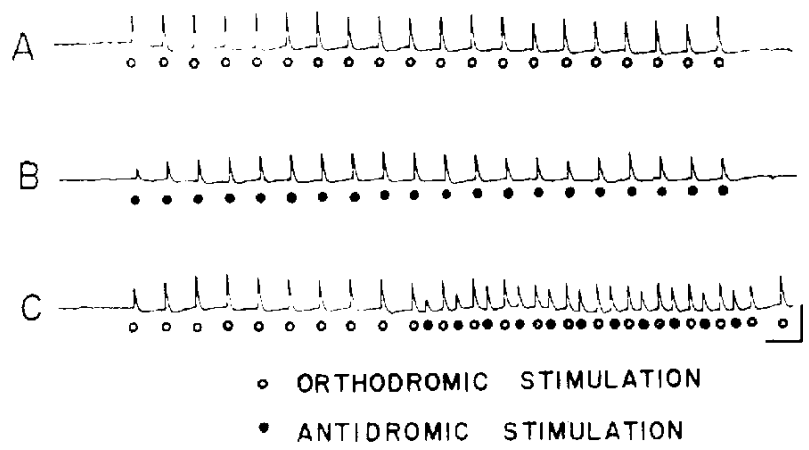

Fig. 6. Junction potentials with marked facilitation in response to ortho-dromic (A ; O) and anti-dromic $(\mathbf{B} ; \mathbf{0})$ repetitive stimulation $(\mathbf{1 ~ H z})$ of the hypogastric nerve in mouse vas deferens. $\mathrm{C}$; when facilitation of junction potentials in response to ortho-dromic repetitive stimulation (O) reached maximum, antidromic stimulation (O) was added. Junction potentials in response to the anti-dromic repetitive stinulation produced facilitation, regardless of the presence of ortho-dromic repetitive stimulation. Time calibration; $1 \mathrm{sec}$, Voltage calibration ; $100 \mu \mathrm{V}$.

stimulation. Sometimes, an action potential was generated, the second junction potential being superimposed on the first junction potential. When facilitation of junction potentials in response of ortho-dromic repetitive stimulation with low frequency $(1 \mathrm{~Hz})$ reached a maximum, the junction potentials in response to added anti-dromic repetitive stimulation ( $1 \mathrm{~Hz}$ ) caused marked facilitation (Fig. 6). This finding indicates that the facilitation of junction potentials is produced only by impulses propagated in the same direction along the terminal nerve fibers, and also that the origin of facilitation of junction potentials is al a pre-junctional site.

\section{DISCUSSION}

Falck (3) has demonstrated that adrenergic neurons form terminals (varicosities) along the length of terminal axons. Furness (4) has concluded that chemical transmitter is released from these varicosities, from the result that anti-dromic hypogastric nerve stimulation gives rise to junction potentials in mouse vas deferens. In the present experiments, it was found that when the stimulating electrode was shifted further away from recording electrode in the lesticular direction (anti-dromic stimulation), the amplitude of the junction potential became smaller; while when the stimulating electrode was shifted from the recording electrode in the prostatic direction, the amplitude of junction potentials was almost unaltered. The finding may be explained by making the assumption that the amplilude of junction potentials is dependent on the number of nerve fibers excited by orthoand anti-dromic stimulation, since Zieher and Jaim-Etcheverry (9) have demonstrated that innervation is denser on the prostatic side of the vas deferens than on the testicular side. Thus Furness's observation (4) that anti-dromic stimulation produces junction potential was also confirmed by another method. 
Ortho-dromic tetanic stimulation depressed the amplitude of junction potential in response to ortho- and anti-dromic stimulation of hypogastric nerve (post-tetanic depression). In the present study, it could not be determined whether the origin of the posttetanic depression is at a pre- or post-junctional site. It may be that the axonal flow of chemical transmitter is not involved in the recovery process from post-tetanic depression, since no time-lag in the recovery was seen between two separated recording electrodes. The direction of the axonal flow is always proximodistal (11).

Ortho- or anti-dromic repetitive stimulation of the hypogastric nerve produced junction potentials with marked facilitation. However, alternate ortho- and anti-dromic stimulation, using the double shock method, of the hypogastric nerve did not produce facilitation of the junction potentials. Therefore, it is concluded that the facilitation of junction potentials is induced by the action potentials propagating in the same direction in the terminal axons. The finding may also indicate that the origin of the facilitation of the junction potentials is at a presynaptic site. Holman (2) also demonstrated that the facilitation of junction potentials was not due to a progressive increase in sensitivity of the smooth muscle membrane for a constant amount of transmitter; viz. While there was no obvious change in the amplitude of spontancous miniature potentials, junction potentials in response to nerve stimulation were facilitated.

\section{REFERENCES}

1) Burnstock, G. And Holmax, M.E.: I. Physiol. 155, 115 (1961)

2) Holman, M.E.: Pharmacology of Smooth Miscle. Edited by E. Bülbring, Vol, 6, p. 19, Pergamon Press, Praha (1964)

3) Flack, B.: Acta physiol. scaid. Suppl. 197, 1 (1962)

4) Furness, J.B.: Europ. J. Physiol. 314, 1 (1970)

5) Nakanishi, H., Tanaka, H. and Takfoa, H.: Folia pharmacol, japon. 69, 997 (1973) (in Japanese)

6) S.östrand, N.O.: Acta physiol. scand. 54, 306 (1962)

7) Ferry, C.B.: J. Physiol. 166, 16p (1963)

8) Falck, B., Owman, Ch. and Sjöstrand, N.O.: Experientia 21, 98 (1965)

9) Zieher, L.M. and Jaim-Etcheverry, G.: J. Pharm. Pharmacol. 23, 61 (1971)

10) Tomita, T.: J. Physiol. 189, 163 (1967)

11) Geffin, L.B., Hutre, C. And Rush, R.A.: J. Neurochem. 16, 469 (1969) 